\title{
Validated HPTLC Analysis Method for Quantification of Ricinoleic Acid and Oleic Acid Content in Castor Oil, Olive Oil and Selected Market Formulations
}

\section{Marwa E Hassan $^{1 *}$ and Mona H Hetta ${ }^{2}$}

${ }^{1}$ Phytochemistry Department, National Organization for Drug Control and Research (NODCAR), Egypt

${ }^{2}$ Pharmacognosy Department, Fayoum University, Fayoum, Egypt

*Corresponding Author: Marwa E Hassan, Phytochemistry Department, National Organization for Drug Control and Research (NODCAR), Egypt.

Received: March 18, 2019; Published: May 09, 2019

DOI: $10.31080 /$ ASPS.2019.03.0277

\begin{abstract}
Ricinoleic and oleic acids are classified as unsaturated omega-9 fatty acids. Ricinoleic acid naturally occurring fatty acid in the mature castor plant (Ricinus communis L.) and constitutes about $90 \%$ of castor oil components while oleic acid is the most common fatty acid in nature and its triglycerides comprise the majority of olive oil (Olea europaea L.). Fixed oils methyl ester are often quantified by gas chromatography (GC) technique. In this work, a new, simple, low-cost, rapid, specific, precise and accurate highperformance thin layer chromatographic (HPTLC) method was developed and validated according to ICH guidelines for the routine analysis of ricinoleic acid and oleic acid methyl esters in pure castor and olive oils and their formulations. Oil methyl esters were analyzed by GC, HPLC and HPTLC techniques as comparative analyses. Results obtained by the HPTLC method were statistically compared with those obtained by the reported GC and HPLC methods. For the proposed procedure, linearity, limit of detection, limit of quantification and recovery were found to be satisfactory. It could be concluded that proposed HPTLC technique can be used as alternative method for the quality control of the raw materials as well as formulations containing castor and olive oils calculated as ricinoleic and oleic acids respectively as it is simple, cost-safe, rapid and specific.
\end{abstract}

Keywords: HPTLC, validation, castor oil, olive oil, fatty acid methyl ester.

\section{Introduction}

Castor oil is a vegetable oil obtained by pressing the seeds of the castor oil plant (Ricinus communis L., Euphorbiaceae) [1,2]. Almost $90 \%$ of fatty acids content of castor oil is ricinoleic acid which is unique for castor oil. Such a high concentration of this unusual, unsaturated fatty acid is thought to be responsible for castor oil's remarkable healing abilities [3]. Castor oil is a natural fixed oil which, in its native state, has many uses ranging from personal care products (as laxatives and cosmetics), to chemical manufacturing (raw materials), and to industrial materials (lubricants, hydraulic fluids, dielectric fluids, textiles, paints, coatings) and recently ricinoleate methyl esters are used as raw material for biodiesel production [4]. The composition of castor oil is unique in that it contains a triglyceride formed of an omega- 9 unsaturat- ed fatty acid, 12-hydroxy-9-cisoctadecenoic acid (ricinoleic acid) ninety percent of the total triglycerides are triricinoleate [5]. It is reported that the components of the fatty-acid fraction of castor oil analysed by GC were ricinoleic acid methyl ester (85 -95\%), palmitic acid methyl ester (maximum $0.5 \%$ ), stearic acid methyl ester (maximum $1.5 \%$ ), oleic acid methyl ester (2 - 6\%), linoleic acid methyl ester (2- 5\%), linolenic acid methyl ester (maximum 1\%) and eicosenoic acid methyl ester ( maximum 0.5\%) [6]. Castor oil is carrying off the phlegm from the stomach as a home cough remedy. The thick, fatty consistency of castor oil is thought to coat and soothe the throat [7]. Ricinoleic acid has been shown to be effective as antiviral and antimicrobial agent [8]. It is also having antioxidant activities [9]. Olive oil composition includes a large proportion of unsaturated fatty acids (oleic, linoleic and linolenic acids), vitamins (A, E and $\beta$-carotene) and phenolic compounds or chemicals pres- 
ent in the unsaponificable fraction [10]. Olive oil is unique with respect to the high oleic acid content. Oleic acid and linoleic acid are the main components, representing from 55 to $83 \%$ and from 5 to $15 \%$ of the total fatty acids, respectively [11]. Squalene and $\beta$-carotene are present in olive oil; squalene is responsible for the beneficial health activates of olive oil and its chemopreventive action against certain cancers [12]. A recent study found virgin olive oil has bactericidal action against Helicobacter pylori [13]. Oleuropein from olive oil lowers postprandial glycaemia [14]. Olive oil has anti-inflammatory [15] and antioxidant activities [16]. Oleic acid plays a role in cancer prevention [17]. Fixed oil methyl esters are usually analyzed by GC [18]. Other techniques as HPLC [19] are rarely used for their analysis. The aim of this work is to develop and validate an accurate, simple, low-cost, rapid, specific and powerful HPTLC method for ricinoleic and oleic acids methyl esters analysis as a tool for quick and easy determination of quality, authenticity and purity of crude drug and formulations. The HPTLC result was statistically compared with those obtained by the reported GC and HPLC methods.

\section{Materials and Reagents}

Materials

The standards (ricinoleic acid, oleic acid) were purchased from Sigma (Aldrich) and assigned purity of 98\%, 95\%. Castor and olive oils sample were purchased from EVA Company. Tested formulations; T1 (syrup): (propolis, lemon oil, honey and castor oil), T2 (capsule): (castor oil), T3 (cream): (olive oil, bee wax and jojoba oil) and T4 (hair oil): (aloe vera, rosemary oil, vit.A and olive oil), were obtained from the Egyptian market.

Solvents and reagents

Anisaldehyde (Merck, Germany) reagent was used for visualization. P-anisaldehyde- sulphuric acid reagent was prepared according to Wagner and Bladt [20]. The solvents used (toluene, ethyl acetate, n-hexane, methanol, benzene, sulphuric acid, glacial acetic acid) were obtained from Adwic, Egypt and assigned purity of $98 \%$ and the water used was deionized (NODCAR, Egypt). Acetonitrile and methanol used were of HPLC grade (Merck, Germany) and assigned purity of $98.9 \%$.

\section{Instruments}

\section{Gas chromatography (GC)}

Hewlett-Packard 6890 series GC equipped with a flame ionization detector (FID) and an electronic pressure control (EPC) injector (split-split less) was used. A polar HP-5 (Crosslinked 5\% Phenyl Methyl Siloxane) HP INNO wax (cross linked PEG) (30m X $0.32 \mathrm{~mm}$ X 0.5um), Carrier gas: Nitrogen $40 \mathrm{~cm} / \mathrm{sec}, 11.8$ Psi $\left(50^{\circ} \mathrm{C}\right)$.
High performance liquid chromatographic (HPLC)

Agilent HPLC (USA) 1260 infinity and consisted of a quaternary pump and UV detector equipped with sampler TCC, under computer control was used.

\section{High performance thin layer chromatography (HPTLC)}

The samples were spotted in the form of bands with a Camag micro liter syringe on precoated silica gel ready-made aluminum plate $60 \mathrm{~F}_{254}(20 \mathrm{~cm} \times 10 \mathrm{~cm}$ with $0.2 \mathrm{~mm}$ thickness; E. Merck, Darmstad, Germany) using a sample applicator for TLC Linomat V (CAMAG, Muttenz, Switzerland). Plates were developed in ascending order with a CAMAG twin trough glass tank which was pre-saturated with the mobile phase for $15 \mathrm{~min}$. TLC runs were performed under laboratory conditions (Temp: $25 \pm 2^{\circ} \mathrm{C}$ and \% RH: $60 \pm 5$ ). Densitometric analysis was performed with a Camag TLC scanner III operated by Win CATS software (Version 1.2.0). The source of radiation utilized was deuterium and Tungsten lamp.

Preparation of methyl ester of fatty acids standard, oils and test solutions

Ten $\mathrm{ml}$ of T1, 100mg of T2, 100mg of T3, $10 \mathrm{ml}$ of T4, $50 \mathrm{mg}$ of castor oil (S1), $50 \mathrm{mg}$ of olive oil (S2), $5 \mathrm{mg}$ ricinoleic acid (S3) and $5 \mathrm{mg}$ oleic acid (S4) were separately methylated using a solution of diazomethane in diethylether [21] and refluxed for $2 \mathrm{hr}$ at $80^{\circ} \mathrm{C}$ then cooled and extracted with $\mathrm{n}$-hexane $(3 \times 10 \mathrm{ml})$ then concentration of solutions to $10 \mathrm{ml}$ and finally transferred to a volumetric flask.

Preparation of calibration curve of ricinoleic and oleic acids by HPTLC

A Stock solution of ricinoleic acid and oleic acid (100 mg) were separately converted to methyl esters as described above. The solution was further diluted with n- hexane to yield a solution containing $100 \mu \mathrm{g} / \mathrm{ml}$. Different concentration of both acids methyl ester were applied on plates as $6 \mathrm{~mm}$ bands on TLC plate separately. The data of peak area versus the corresponding standard concentration were treated by linear least-square regression.

\section{Chromatographic conditions}

Gas chromatography (GC) conditions for analysis of methyl ester of ricinoleic and oleic acids

Flow: Constant flow $1 \mathrm{ml} / \mathrm{min}$, injector: Split mode (100:1), $0.5 \mu \mathrm{l}$ injection volume, inlet temp. $220^{\circ} \mathrm{C}$, oven temperature program: initial temp: $120^{\circ} \mathrm{C}$, initial time: $3 \mathrm{~min}$, rate: $10^{\circ} \mathrm{C} / \mathrm{min}$, final temp: $300^{\circ} \mathrm{C}$, final time: $5 \mathrm{~min}$, Detector temp. $275^{\circ} \mathrm{C}$. The detector air flow was $200 \mathrm{ml} / \mathrm{min}$ and hydrogen flow was $20 \mathrm{ml} / \mathrm{min}(10 \%$ of air flow). 
High performance liquid chromatography (HPLC) conditions for analysis of methyl ester of ricinoleic and oleic acids

All analyzed compounds were separated on a lichrospher C18 for ricinoleic acid and C8 for oleic acid $(10 \mu \mathrm{m})$ column (250 x 4.6mm) I.D. Merck, Darmstadt, Germany. Mobile phase consisting of isopropanol/ methanol/ water (60:35:5) and UV detection at $205 \mathrm{~nm}$ for ricinoleic acid and acetonitrile / water (85: $15 \mathrm{v} / \mathrm{v}$ ), and UV detection at $242 \mathrm{~nm}$ for oleic acid.

High performance thin layer chromatography (HPTLC) Conditions of for analysis of methyl ester of ricinoleic and oleic acids

The samples were spotted in the form of bands of width $6 \mathrm{~mm}$ with a micro liter syringe on precoated silica gel ready-made aluminum plate $60 \mathrm{~F}_{254}$. A constant application rate of $150 \mathrm{~nL} / \mathrm{s}$ was employed with a space between two bands of $5 \mathrm{~mm}$. The slit dimension was kept at $6 \mathrm{~mm} \times 0.3 \mathrm{~mm}$, and $20 \mathrm{~mm} / \mathrm{s}$ scanning speed was employed. These parameters were kept constant throughout the analysis of samples. The mobile phase consisted of toluene. The length of each run was $8 \mathrm{~cm}$ and then air dried. Densitometric analysis was performed at $450 \mathrm{~nm}$. The composition of the mobile phase for TLC was optimized using different solvents of varying polarity and good resolution was achieved using toluene as mobile phase. Rf value for ricinoleic and oleic acids was found to be $0.78 \pm 0.02$ and $0.67 \pm 0.02$ respectively. After spraying with anisaldehyde/ sulphuric acid using automatic sprayer (CAMAG), the scanning selected wavelength was $450 \mathrm{~nm}$ as it is the absorption maxima of the both acids spots.

\section{Method of validation}

The developed method was validated in terms of linearity, precision, limits of detection (LOD), limits of quantification (LOQ), and recovery according to International Conference on Harmonization guidelines (ICH) guidelines [22].

\section{Precision}

The intra-day precision of the assay evaluated by performing triplicate analyses $(n=3)$ for the sample. The inter-day precision of the assay was determined and repeated on three different days.

\section{Linearity}

Due to verification of the normal distribution of results, linearity was evaluated through the relationship between the concen- tration of ricinoleic acid methyl ester and the area obtained from TLC scanner. The determination coefficient $\left(\mathrm{r}^{2}\right)$ was calculated. The calibration line was achieved through two replicates of each concentration of ricinoleic acid methyl ester to know the extent of the total variability of the response that could be explained by the linear regression model.

\section{Limit of detection (LOD) and limit of quantification (LOQ)}

The limit of detection (LOD) is the lowest amount of fatty acids methyl ester in a sample that can be detected but not necessary quantitated. The limit of quantitation (LOQ) is the lowest amount of fatty acids methyl ester in a sample that can be quantitatively determined with suitable precision and accuracy. The limits of quantification and detection were determined based on the technique of signal-to-noise ratio using the equations (1) and (2):
$\mathrm{LOQ}=10 \sigma / \mathrm{S}(1)$
$\mathrm{LOD}=3.3 \sigma / \mathrm{S}(2)$

Where $\sigma$ is the standard deviation of the intercept of the calibration curve and $\mathrm{S}$ is the slope of the calibration curve.

\section{Specificity}

The specificity of the method was ascertained by analyzing standard drug and sample. The spot for both acids methyl esters in sample was confirmed by comparing $\mathrm{R}_{\mathrm{f}}$ and spectra of the spot with that of castor, olive oils and formulations. The peak purity of ricinoleic and oleic acids methyl ester was assessed by comparing the spectra at three different levels: peak start, peak apex and peak end positions of the spot.

\section{Recovery}

This parameter shows the proximity between the experimental values and the real ones. It ensures that no loss or uptake occurred during the process. The determination of this parameter was performed for the method by studying the recovery after a standard addition procedure with two additional levels. In each additional level, three determinations were carried out and the recovery percentage was calculated in every case. Each sample was injected three times in HPTLC.

\section{Statistical analysis}

Data were reported as mean \pm SD. The results were analyzed statistically by SPSS software and the One-way ANOVA test with level of significance set at $\mathrm{p}<0.05$ was accepted as being significant in statistical test as shown in (Table 1 and Figure 1 and 2). 


\begin{tabular}{|c|c|c|c|c|c|}
\hline \multicolumn{2}{|l|}{ Sample } & (I) experiment & (J) experiment & Mean Difference (I-J) & Standard Error \\
\hline \multirow{6}{*}{$\begin{array}{l}\text { Ricinoleic } \\
\text { acid }\end{array}$} & \multirow[t]{6}{*}{ LSD } & \multirow[t]{2}{*}{ GC } & HPLC & 0.36667 & 0.37417 \\
\hline & & & HPTLC & $1.30000^{*}$ & 0.37417 \\
\hline & & \multirow[t]{2}{*}{ HPLC } & GC & -0.36667 & 0.37417 \\
\hline & & & HTLC & $0.93333^{*}$ & 0.37417 \\
\hline & & \multirow[t]{2}{*}{ HPTLC } & GC & $-1.30000^{*}$ & 0.37417 \\
\hline & & & HPLC & $-0.93333^{*}$ & 0.37417 \\
\hline \multirow[t]{6}{*}{ Oleic acid } & \multirow[t]{6}{*}{ LSD } & \multirow[t]{2}{*}{ GC } & HPLC & 0.20000 & 0.24402 \\
\hline & & & HPTLC & 0.24333 & 0.24402 \\
\hline & & \multirow[t]{2}{*}{ HPLC } & GC & -0.20000 & 0.24402 \\
\hline & & & PHTLC & -0.44333 & 0.24402 \\
\hline & & \multirow[t]{2}{*}{ HPTLC } & GC & 0.24333 & 0.24402 \\
\hline & & & HPLC & 0.44333 & 0.24402 \\
\hline
\end{tabular}

Table 1: Comparative statistical analysis of results obtained using three different chromatography techniques.

*The mean difference is significant at $p<0.05$ level.

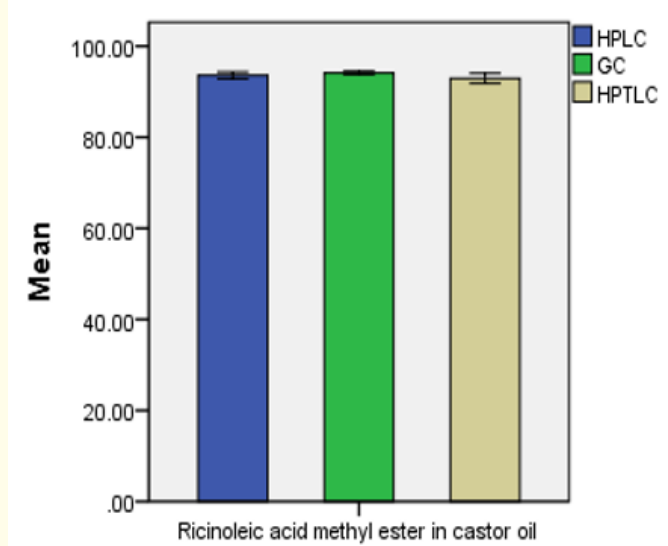

Figure 1: Comparison between HPTLC, GC and HPLC techniques for analysis of ricinoleic acid methyl ester in castor oil.

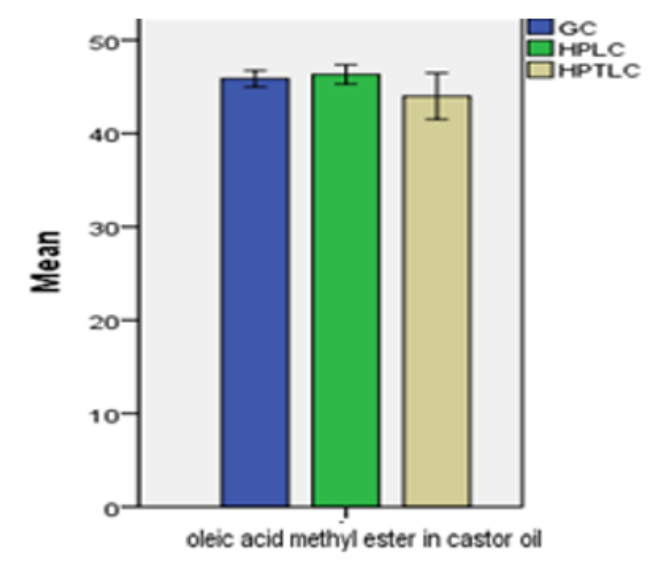

Figure 2: Comparison between HPTLC, GC and HPLC techniques for analysis of oleic acid methyl ester in olive oil.

\section{Results and Discussion}

GC is a common method for assay of fatty acids methyl esters in fatty oils and has been reported for the quantification of these compounds. But it has some limitations to be used for complicated samples. Therefore, this research has been focused on the separation and quantification of ricinoleic and oleic acids methyl ester by validated HPTLC method and comparing the results with those of GC and HPLC techniques. Ricinoleic acid methyl ester peak was observed at the retention time $9.9 \mathrm{~min}$ in GC chromatogram and at 5 min in HPLC chromatogram with Rf 0.78 in HPTLC chromatogram. Whereas oleic acid methyl ester peak was observed at the retention time $7.4 \mathrm{~min}$ in GC chromatogram and at $2.5 \mathrm{~min}$ in HPLC chromatogram with Rf 0.67 in HPTLC chromatogram as shown in (Figure 3 and 4). Quantization results showed ricinoleic acid methyl ester in castor oil by HPLC (93.7\%), GC (94.1\%), HPTLC (92.8\%) and oleic acid methyl ester in olive oil by HPLC (82.7\%), GC (83\%) and HPTLC (81.8\%) as shown in (Table 2).

\begin{tabular}{|l|c|c|c|c|}
\hline Compound & Method & $\begin{array}{c}\text { Mean } \\
\text { (conc. \% w/w) }\end{array}$ & SD & \% RSD \\
\hline \multirow{2}{*}{$\begin{array}{l}\text { Ricinoleic acid } \\
\text { methyl ester }\end{array}$} & HPTLC & $92.83 \%$ & 0.28868 & 0.33 \\
\cline { 2 - 5 } & GC & $94.13 \%$ & 0.56862 & 0.629 \\
\cline { 2 - 5 } & HPLC & $93.76 \%$ & 0.47258 & 0.791 \\
\hline $\begin{array}{l}\text { Oleic acid } \\
\text { methyl ester }\end{array}$ & HPTLC & $81.85 \%$ & 0.393 & 0.412 \\
\cline { 2 - 5 } & GC & $83 \%$ & 0.298 & 0.398 \\
\cline { 2 - 5 } & HPLC & $82.7 \%$ & 0.652 & 0.812 \\
\hline
\end{tabular}

Table 2: HPTLC, GC and HPLC comparative methods for analysis of ricinoleic acid and oleic acid methyl esters. SD: standard deviation; RSD: relative standard deviation 


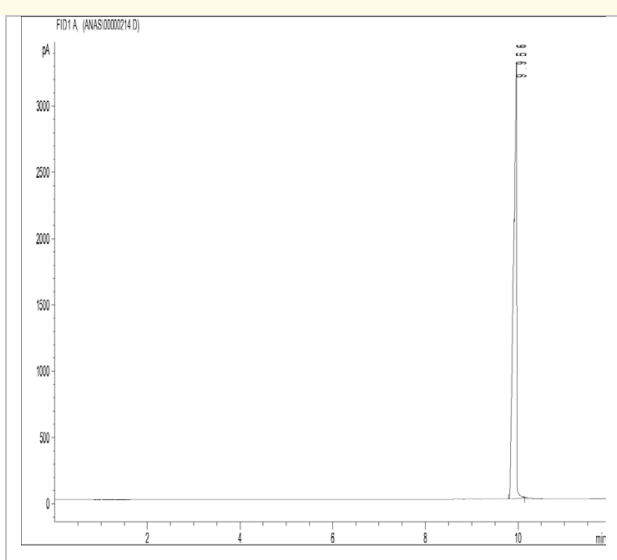

GC chromatogram of ricinoleic acid methyl ester standard (S1)

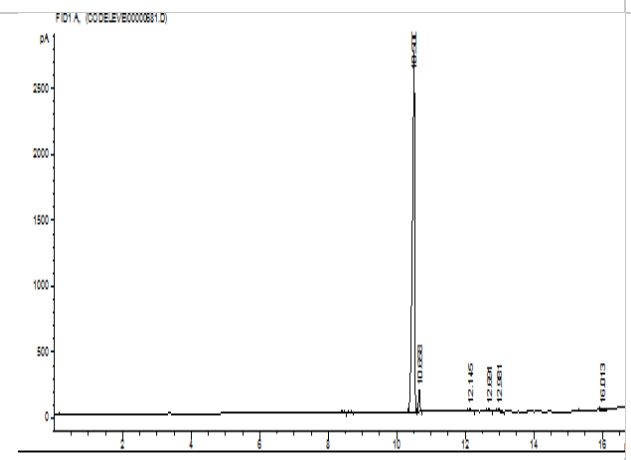

GC chromatogram of oleic acid methyl ester standard (S2)

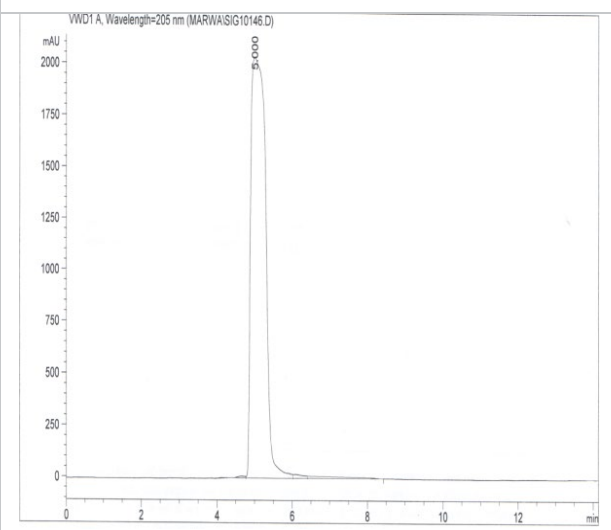

HPLC chromatogram of ricinoleic acid methyl ester standard (S1)

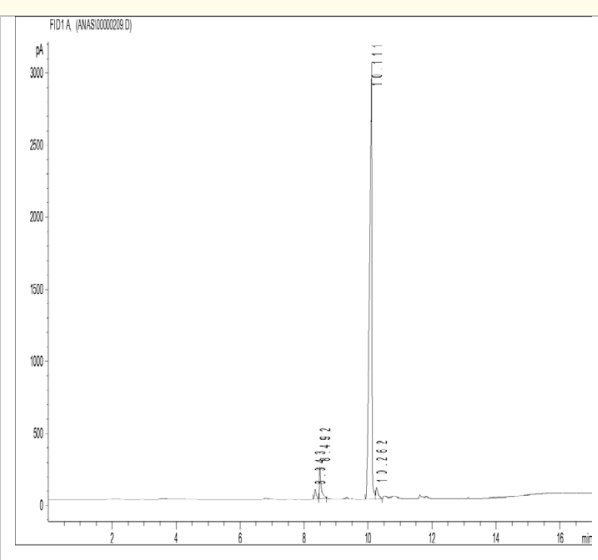

GC chromatogram of castor oil methyl ester standard (S3)

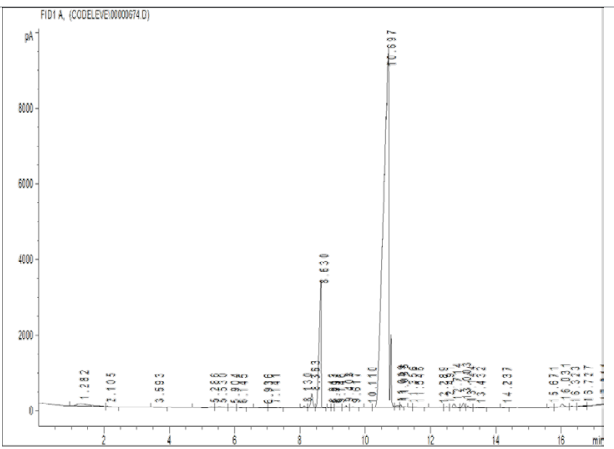

GC chromatogram of olive oil methyl ester standard (S4)

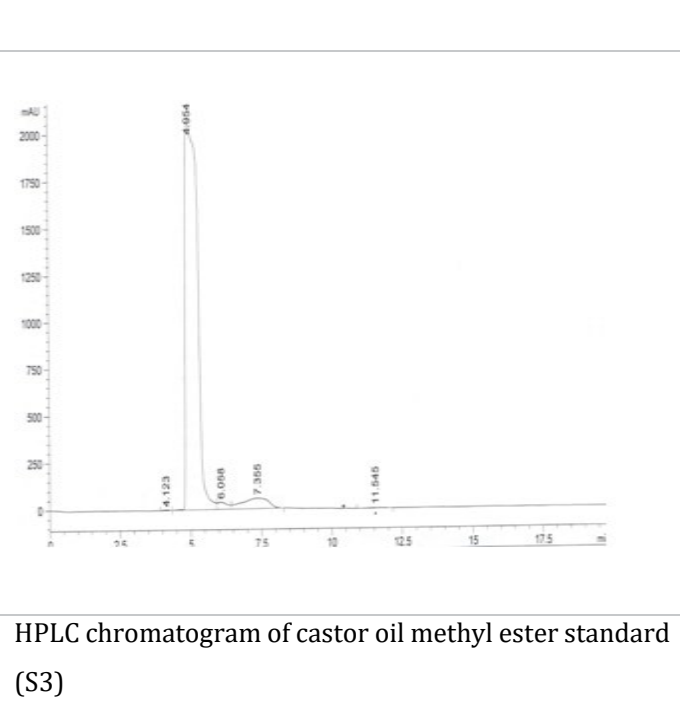




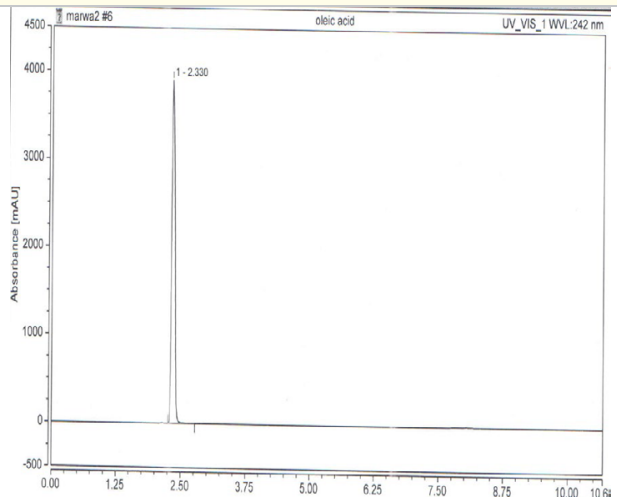

HPLC chromatogram of oleic acid methyl ester standard (S2)

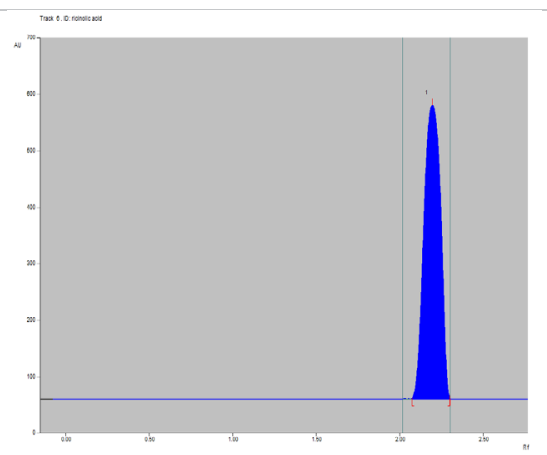

HPTLC chromatogram of ricinoleic acid methyl ester standard (S1)

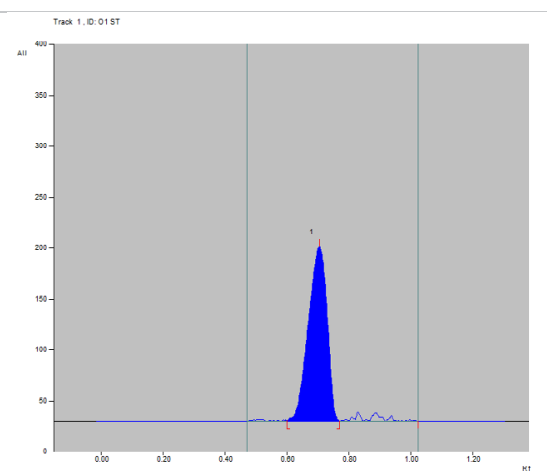

HPTLC chromatogram of oleic acid methyl ester standard (S2)

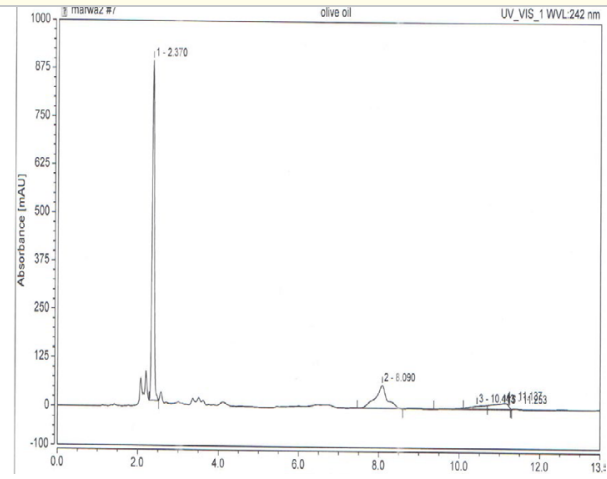

HPLC chromatogram of olive oil methyl ester standard (S4)

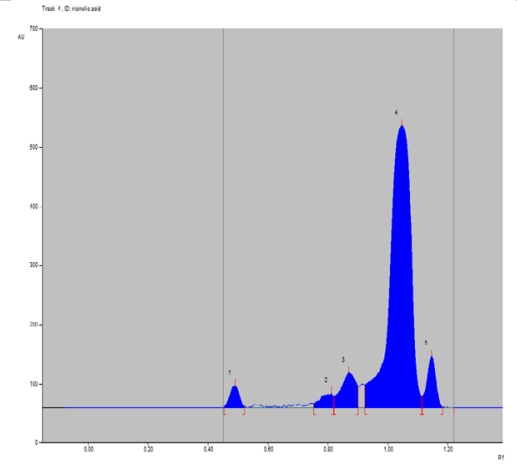

HPTLC chromatogram of castor oil methyl ester standard (S3)

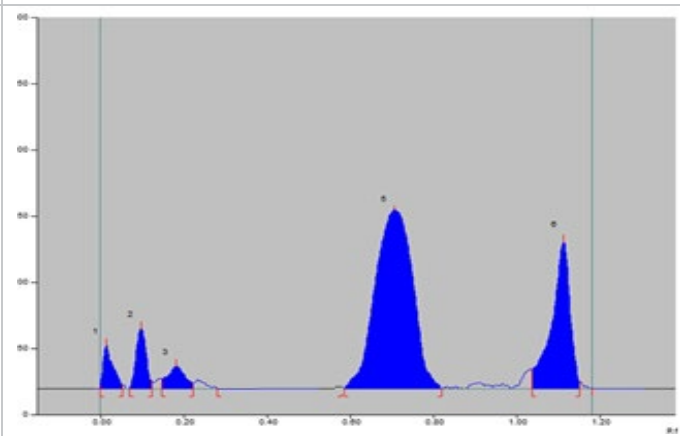

HPTLC chromatogram of olive oil methyl ester standard (S4)

Figure 3: GC, HPLC and HPTLC chromatograms of ricinoleic acid, oleic acid, castor oil and olive oil methyl esters. 


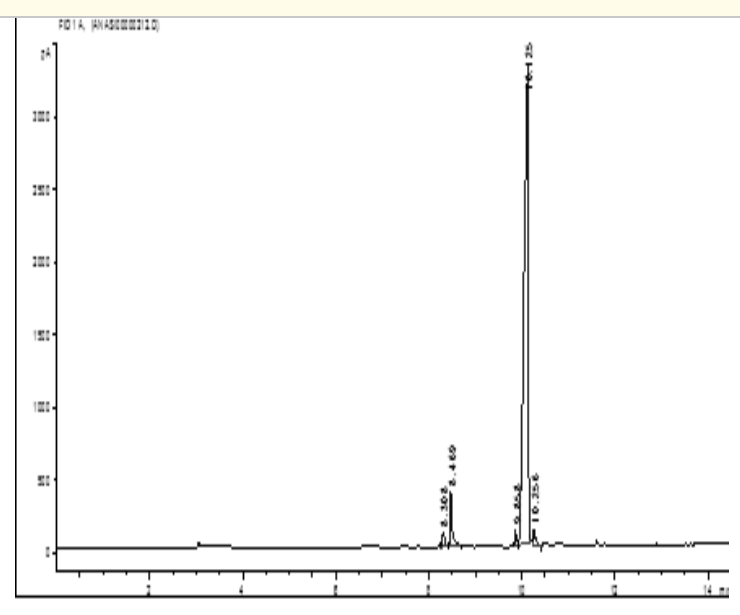

GC chromatogram of T1

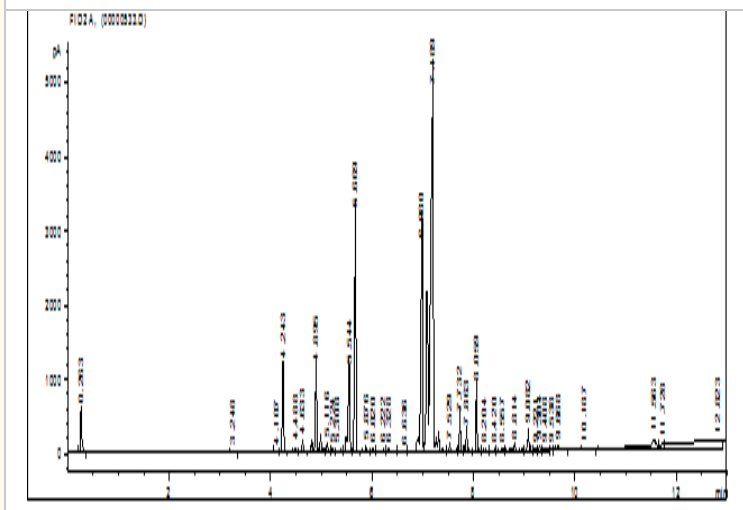

GC chromatogram of T3

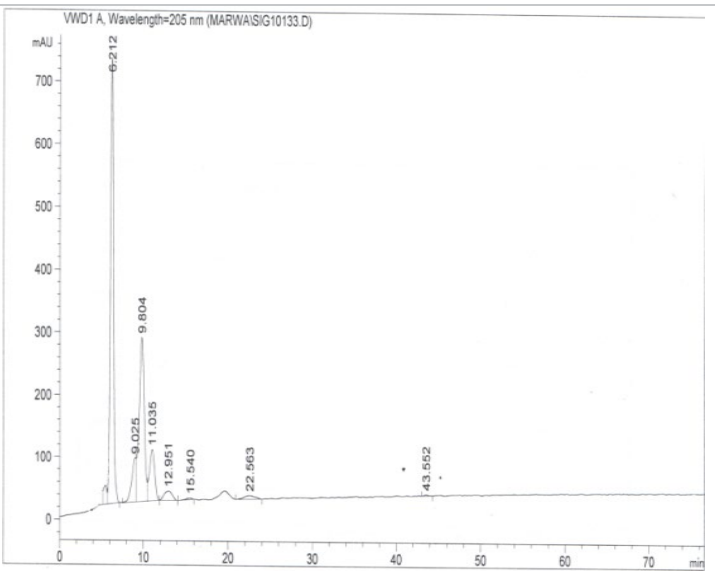

HPLC chromatogram of T1

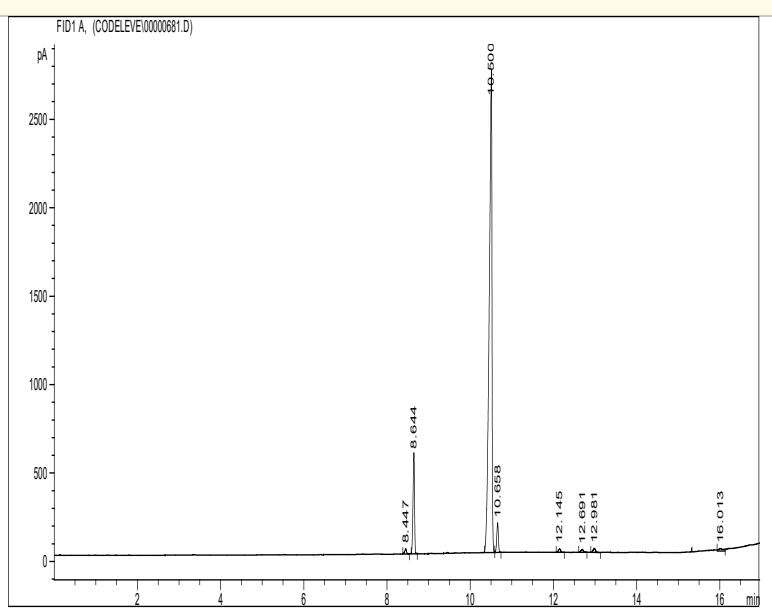

GC chromatogram of T2

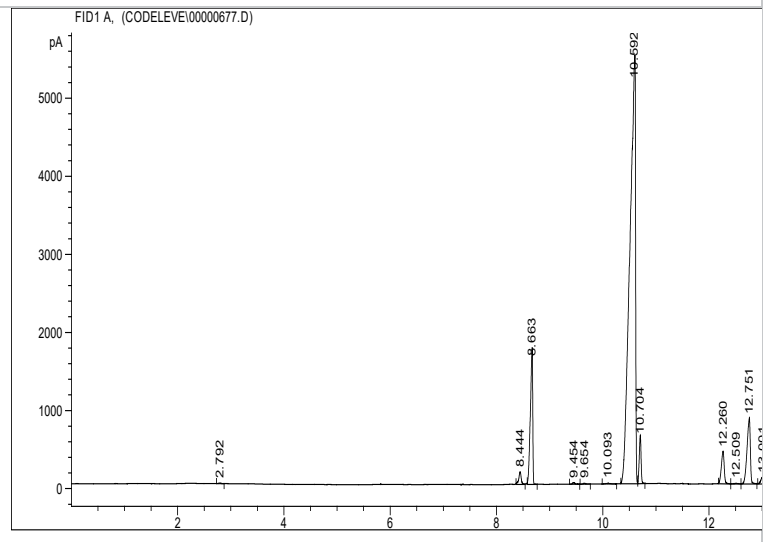

GC chromatogram of T4

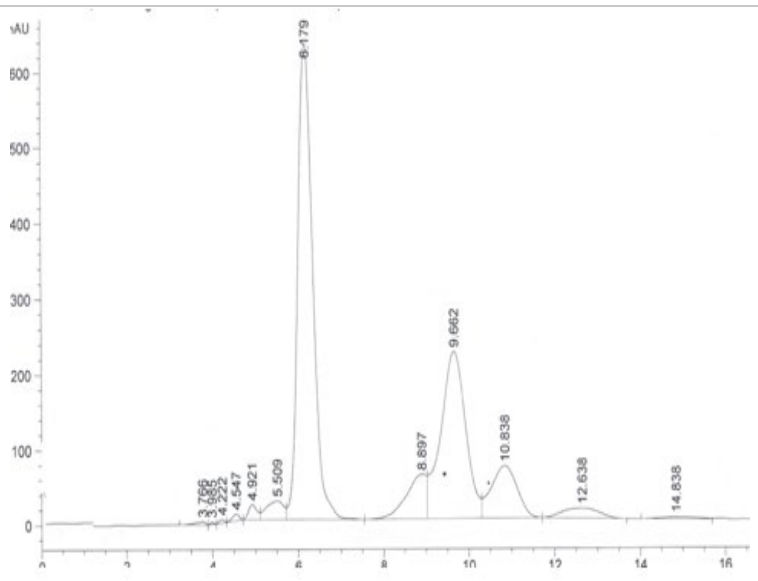

HPLC chromatogram of T2 

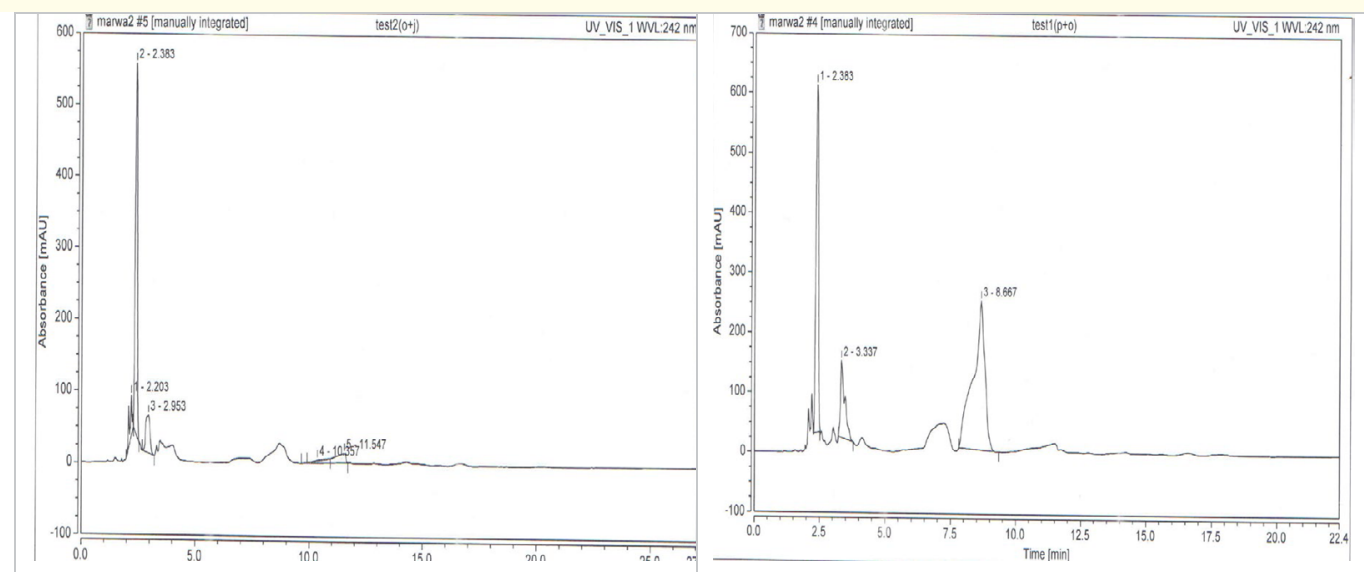

HPLC chromatogram of T3

HPLC chromatogram of test formulation (T4)
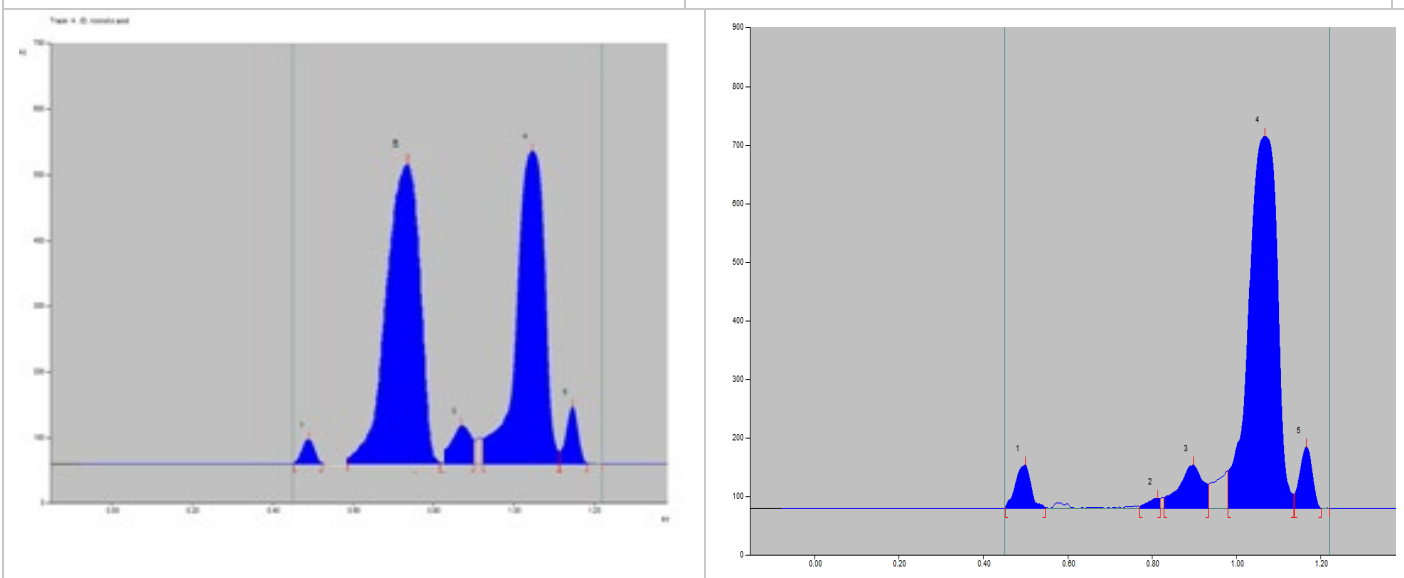

HPTLC chromatogram of T1

HPTLC chromatogram of T2
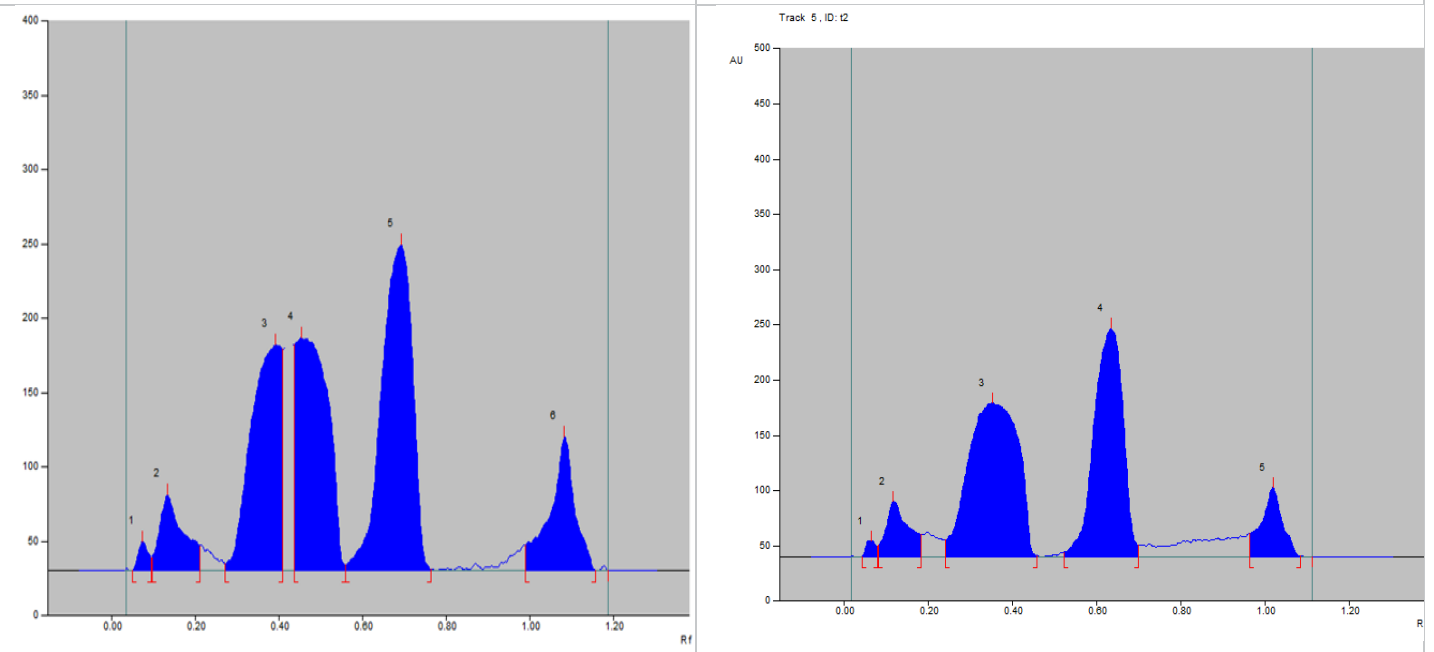

HPTLC chromatogram of T3

HPTLC chromatogram of T4

Figure 4: GC, HPLC and HPTLC chromatograms of tested formulations methyl ester. 
Development and optimization of mobile phase

Toluene/ ethyl acetate mobile phase was used in different ratio. The latter at $(9.3: 0.7 \mathrm{v} / \mathrm{v})$ showed good resolution with $\mathrm{Rf}$ value of $0.95 \pm 0.02$ for ricinoleic acid methyl ester but the spot was on the solvent front and with no complete separation for oleic acid spot. The ratio of the mobile phase was varied and we determined the effect on $\mathrm{Rf}$ and on the response to ricinoleic and oleic acids methyl esters. The mobile phase consisting of toluene only showed a sharp and well-defined peak at Rfvalue of $0.78 \pm 0.02$ for ricinoleic acid methyl ester and $0.67 \pm 0.02$ for oleic acid methyl ester. Well-defined spots were obtained when the chamber was saturated with the mobile phase at room temperature for $15 \mathrm{~min}$. For determination of the linearity curves of area vs. concentrations, different amounts of stock solution of both acids methyl esters were applied on the HPTLC plate and analyzed.

\section{Method validation}

Linearity and range

The calibration was linear, the linear regression equation was $Y$ $=1720.9 x+1633$, for ricinoleic acid methyl ester and $Y=105.3 x+3.3$ for oleic acid methyl ester, while the correlation coefficient (r2) was 0.9993 and 0.999 respectively, with high reproducibility and accuracy as shown in (Table 3 and Figure 5 and 6).

\begin{tabular}{|l|c|c|}
\hline \multirow{2}{*}{ Parameter } & \multicolumn{2}{|c|}{ Results } \\
\cline { 2 - 3 } & $\begin{array}{c}\text { Ricinoleic acid } \\
\text { methyl ester }\end{array}$ & $\begin{array}{c}\text { Oleic acid methyl } \\
\text { ester }\end{array}$ \\
\hline Linearity range & $0.5-3 \mu \mathrm{g} / \mathrm{band}$ & $5-25 \mu \mathrm{g} / \mathrm{band}$ \\
\hline $\begin{array}{l}\text { Regression } \\
\text { equation }\end{array}$ & $\mathrm{Y}=1720.9 \mathrm{x}+1633$ & $\mathrm{Y}=105.3 \mathrm{x}+3.3$ \\
\hline $\begin{array}{l}\text { Correlation } \\
\text { coefficient }\end{array}$ & 0.9993 & 0.999 \\
\hline Recovery & $98.3 \%-102 \%$ & $98.5 \%-101.9 \%$ \\
\hline $\begin{array}{l}\text { Intra-day preci- } \\
\text { sion (\%RSD) }\end{array}$ & 0.29 & 0.99 \\
\hline $\begin{array}{l}\text { Inter-day preci- } \\
\text { sion (\%RSD) }\end{array}$ & $1.2,1.2 \mathrm{and} 1.04$ & $1.31,1.38$ and 1.37 \\
\hline LOD & $3.1 \mu \mathrm{g} / \mathrm{spot}$ & $1.4 \mu \mathrm{g} / \mathrm{spot}$ \\
\hline LOQ & $9.4 \mu \mathrm{g} / \mathrm{spot}$ & $4.2 \mu \mathrm{g} / \mathrm{spot}$ \\
\hline
\end{tabular}

Table 3: Analytical parameter for determination of ricinoleic and oleic acids methyl esters using HPTLC technique.

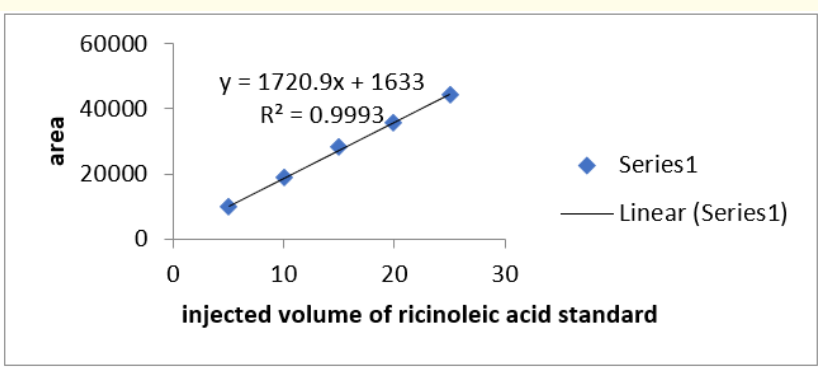

Figure 5: Calibration curve of ricinoleic acid methyl ester standard using HPTLC technique.

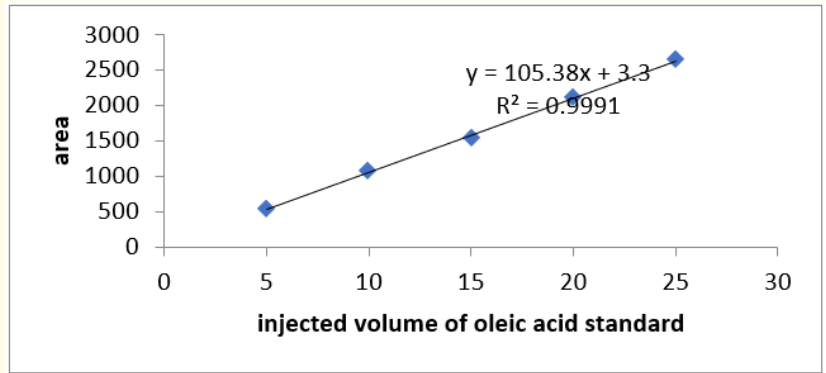

Figure 6: Calibration curve of oleic acid methyl ester standard using HPTLC technique.

\section{Recovery studies}

The proposed method was used for estimation of both acids methyl esters after a standard addition procedure with two additional levels. In each additional level, three determinations were carried out and the recovery percentage afforded range from $98 \%$ $-102 \%$ for both acids methyl ester as shown in (Table 3).

Limit of detection (LOD) and limit of quantification (LOQ)

LOD of ricinoleic acid and oleic acid methyl esters was determined by plotting series of concentrations on the plate and scanning at $450 \mathrm{~nm}$. The lowest amount of ricinoleic acid and oleic acid methyl esters which could be detected (LOD), was $3.1 \mu \mathrm{g} / \mathrm{spot}$ and $1.4 \mu \mathrm{g} /$ spot respectively. The lowest amount of ricinoleic acid and oleic acid methyl esters which could be quantified (LOQ), was found to be $9.4 \mu \mathrm{g} /$ spot and $4.2 \mu \mathrm{g}$ /spot respectively as shown in (Table 3). 


\section{Specificity}

The specificity of the proposed method was determined by comparing the sample and standard peak for its $\mathrm{R}_{\mathrm{f}}$ and area. The three point peak purity was found superimposed. This indicated that standard fatty acids methyl ester and sample peaks were not merging with any other components or impurities. The peak purity of ricinoleic acid methyl ester was assessed.

\section{Precision and accuracy}

The results indicate that significant intra- and inter day variation in the analysis of ricinoleic acid methyl ester in castor oil and oleic acid methyl ester in olive oil as shown in (Table 3 ).

\section{Conclusion}

This newly established method was validated to be selective, precise and accurate for the quantitative analysis of ricinoleic and oleic acids methyl esters in castor and olive oils and market formulations. It could be concluded that this method is not only a useful tool for the assay of these components but also an effective quality control method to assay fatty acid methyl ester in pharmaceutical dosage forms which could not be analyzed by GC or HPLC. This method can be considered as a good alternative to the already existing methods for the analysis of these compounds in plants.

\section{Bibliography}

1. Alfred T. "Fats and Fatty Oils". Ullmann's Encyclopedia of Industrial Chemistry Wiley-VCH (2005): 1-73.

2. Achaya KT., et al. "The Component Fatty Acids and Glycerides of Castor Oil". Journal of the American Oil Chemists Society (1964): 783-784.

3. Akpan UG., et al. "Extraction, characterization and modification of Castor Seed Oil”. Leonardo Journal of Sciences (2006): 43-52.

4. Goodrum JW and Geller DP. "Influence of fatty acid methyl esters from hydroxylated vegetable oils on diesel fuel lubricity". Journal of Bioresource Technology (2005): 851-855.

5. Jumat S., et al. "Fatty Acid Composition and Physicochemical Properties of Malaysian Castor Bean Ricinus communis L. Seed Oil”. Sains Malaysiana (2010): 761-764.

6. British Pharmacopoeia. 7th edition. Castor oil, London. UK (2014).
7. Patrick Quillin. “Amish Folk Medicine: Home Remedies Using Foods, Herbs and Vitamins". Leader Company (1995).

8. Narasimhan B., et al. "Syntheses and QSAR studies of sorbic, cinnamic and ricinoleic acid derivatives as potential antibacterial agents". Indian Journal of Chemistry (2003): 2828-2834.

9. Ganiyat KO. "Antioxidant activities of methyl ricinoleate and ricinoleic acid dominated Ricinus communis seeds extract using lipid peroxidation and free radical scavenging methods". Research Journal of Medicinal Plant (2012): 511-520.

10. Vichi S., et al. "Analysis of Virgin Olive Oil Volatile Compounds by Headspace Solid-phase Microextraction Coupled to Gas Chromatography With Mass Spectro-metric and Flamme Ionization Detection". Chromatography Journal (2003): 19-33.

11. Visioli F and Galli C. "Olive oil: More than just oleic acid”. American Journal of Clinical Nutrition (2000): 853-856.

12. Waterman $\mathrm{E}$ and Lockwood B. "Active components and clinical applications of olive oil'. Alternative Medicine Review (2007): 331-342.

13. Romero C., et al. "In vitro activity of olive oil polyphenols against Helicobacter pylori”. Journal of Agricultural and Food Chemistry (2007): 680-686.

14. Roberto C., et al. "Oleuropein, a component of extra virgin olive oil, lowers postprandial glycaemia in healthy subjects". British Journal of Clinical Pharmacology 84 (2018): 60-66.

15. Carluccio M., et al. "Olive oil and red wine antioxidant polyphenols inhibit endothelial activation: antiatherogenic properties of Mediterranean diet phytochemicals". Arterioscler, Thrombosis, and Vascular Biology (2003): 622-629.

16. Owen RW., et al. "Phenolic compounds and squalene in olive oils: the concentration and antioxidant potential of total phenols, simple phenols, secoiridoids, lignans and squalene". Food and Chemical Toxicology (2000): 647-659.

17. Visioli F., et al. "Biological activities and metabolic fate of olive oil phenols". European Journal of Lipid Science and Technology (2002): 677-684.

18. Deligiannis A., et al. "Castor (Ricinus communis L.) seed oil as an alternative feed stock for the production of biodiesel". Journal of Environmental Science and Technology China (2009): 3-5.

19. Guarrasi V., et al. "Quantification of underivatized fatty acids from vegetable oils by HPLC with UV detection". Journal of Chromatographic Science (2010): 1-5. 
20. Wagner HB and Bladt St. "Plant Drug Analysis, thin Layer Chromatography" 2nd Edition. (1995): 259- 364.

21. Vogel`s. "Textbook of Quantitative Chemical Analysis". Pearson Education (Singapore) Pte.Ltd. Indian Branch, 482 F.I.E Patparganj, Delhi 110092, India (2000).

22. International Conference on Harmonisation of Technical Requirements for Registration of pharmaceuticals for human use (ICH) guidelines Q2A. Text on Validation of Analytical Procedure, International conference of harmonization, Geneva (2005).

\section{Volume 3 Issue 6 June 2019}

\section{(C) All rights are reserved by Marwa E Hassan and}

\section{Mona H Hetta.}

